\title{
Juventudes, violência e convivência na escola: Uma pesquisa sociopoética
}

\author{
Youth, violence and school living: A sociopoetic research \\ Juventudes, violencia y convivencia en la escuela: Una investigación sociopoética
}

Recebido: 10/06/2021 | Revisado: 18/06/2021 | Aceito: 23/06/2021 | Publicado: 10/07/2021

\author{
Shara Jane Holanda Costa Adad \\ ORCID: https://orcid.org/0000-0001-7711-6325 \\ Universidade Federal do Piauí, Brasil \\ E-mail: Shara_pi@hotmail.com \\ Vanessa Nunes dos Santos \\ ORCID: https://orcid.org/0000-0001-9332-6445 \\ Universidade Federal do Piauí, Brasil \\ E-mail: vanessandsantos@outlook.com \\ Krícia de Sousa Silva \\ ORCID: https://orcid.org/0000-0002-3169-8849 \\ Universidade Federal do Piauí, Brasil \\ E-mail: kriciasousa@hotmail.com
}

\begin{abstract}
Resumo
O presente artigo objetiva analisar a filosofia, de um grupo de jovens, presente na produção de confetos (conceitos + afetos) sobre o tema "violências na relação com a convivência na escola", realizada por grupo-pesquisador formado por 11 jovens, alunos e alunas da $2^{\mathrm{a}}$ e $3^{\mathrm{a}}$ séries do ensino médio integrados a cursos técnicos do Centro Estadual de Educação Profissional "Prefeito João Mendes Olímpio de Melo" PREMEN-NORTE, em Teresina, capital do Piauí. A abordagem metodológica utilizada para a investigação foi a Sociopoética, que reconhece o corpo, a arte e a espiritualidade como potência para a produção coletiva do conhecimento. Conclui que, a partir das linhas de pensamento Tipos de violências e seus efeitos no corpo dos jovens e a convivência na escola e Os sentidos da convivência na relação com as violências, os jovens destacam as violências estabelecidas no cotidiano escolar com a convivência e suas relações pessoais, criticando a banalização das diferentes formas de violências que têm levado a escola a ser consumida por diversos conflitos.
\end{abstract}

Palavras-chave: Violência; Convivência; Sociopoética; Escola; Jovens.

\begin{abstract}
This article aims to analyze the philosophy of a group of young people present in the production of confetti (concepts + affections) on the theme "violence in relation to school living", being carried out by a researcher-group formed by 11 young people, students of 2nd and 3rd grade of high school integrated to technical courses at the State Center for Professional Education "Prefeito João Mendes Olímpio de Melo" PREMEN-NORTE, in Teresina, capital of Piauí. Sociopoetics was the methodological approach used for the investigation, once it recognizes the body, art and spirituality as a power in the collective production of knowledge. It was possible concluded from the lines of thought: Types of violence and its effects on the body of young people and the school living and The meanings of living in relation to violence, that young people highlight the violence established in the school routine with their living and personal relationships, criticizing the trivialization of the different forms of violence that has led the school to be consumed by various conflicts.
\end{abstract}

Keywords: Violence; Coexistence; Sociopoetics; School; Young.

\section{Resumen}

Este artículo tiene como objetivo analizar la filosofía de un grupo de jóvenes presente en la producción de confetos (conceptos + afectos) acerca del tema "violencia en relación a la convivencia en la escuela", siendo realizado por un grupo de investigación formado por 11 jóvenes, estudiantes de la educación secundaria obligatoria (ESO) integrados a cursos técnicos del Centro Estatal de Educación Profesional "Prefeito João Mendes Olímpio de Melo" PREMENNORTE, en Teresina, capital del Piauí. El enfoque metodológico utilizado para la investigación fue el sociopoético que reconoce el cuerpo, el arte y la espiritualidad como un poder en la producción colectiva de conocimiento. Se concluye que a partir de las líneas de pensamiento: Tipos de violencia y sus efectos en el cuerpo de los jóvenes y la convivencia en la escuela y Los significados de la convivencia en la relación con la violencia, los jóvenes destacan la violencia establecida en la vida escolar cotidiana con la convivencia y sus relaciones personales, criticando la banalización de las diferentes formas de violencia que ha llevado a la escuela a ser consumida por diversos conflictos.

Palabras clave: Violencias; Convivencia; Sociopoética; Escuela; Jóvenes. 


\section{Introdução}

O que dizer das violências que envolvem especialmente o jovem, que adentram principalmente as escolas públicas, viram manchete de jornais, transformam-se em discurso científico de entidades locais, nacionais e internacionais? Há, inclusive, quem fale em um caleidoscópio de violência para enfatizar a multiplicidade dessas situações.

Diante disso, cristalizam-se imagens negativas sobre os jovens que permanecem como alvo de intervenções, no sentido de conter um possível risco, conforme a mídia, em larga escala, associam-nos às temáticas ligadas aos problemas sociais - drogas, violências, crimes. Quando não aparecem em primeiro plano como atores, catalisam as atenções públicas no sentido de construir ações e/ou políticas capazes de contornar a marginalidade atribuída as juventudes, especialmente aquelas que vivem nos espaços da periferia da cidade. De forma geral, as instituições e as políticas públicas envolvidas nessa questão visam dirimir, ou pelo menos diminuir, as dificuldades de "integração social" dos jovens em programas de "ressocialização", de capacitação profissional e de encaminhamento para o mercado de trabalho.

Observamos, com frequência, que, apesar das boas intenções contidas nos programas, o que se busca é a contenção real do risco ou potencial desses/as meninos/as. Normalmente a transgressão é associada à ociosidade - ao vazio - pela ausência do trabalho. Tem-se em mente que os próprios jovens são os problemas sociais sobre os quais é necessário intervir, para "salvá-los" e "integrá-los" à ordem social. São vistos sob a lógica do sistema e das instituições, como atores que operam à margem deles ou contra eles: jamais por sua própria lógica. As instituições que formulam ações dirigidas à infância e à juventude enfocam o risco, a ameaça e a desordem que os jovens representam para si e para a sociedade. Essas imagens são paradigmáticas desde os anos 1990, sendo as crianças e os jovens as figuras emblemáticas marcadas pela exclusão e pela violência: meninos/as de rua, adolescentes infratores, gangues, galeras e principalmente jovens em situação de risco para si e para a ordem social (Diógenes, 2020).

Os dados sobre as violências contra crianças, adolescentes e jovens nos documentos estatísticos, que constam no "Atlas da Violência 2019" (Brasil, 2019), evidenciam que o Brasil está entre os 10 países que mais mata jovens no mundo, configurando o cenário nacional de instituições desmoralizadas e a juventude esquecida. Complementando esse cenário de guerra, nos dados do "Atlas da Violência 2020" (Brasil, 2020), no Brasil, os homicídios são a principal causa de mortalidade de jovens, no grupo etário de pessoas entre 15 e 29 anos, em que as vítimas são indivíduos com plena capacidade produtiva, em período de formação educacional e profissional, na perspectiva de iniciar a construir uma rede familiar própria. Aqui é importante pararmos para refletir sobre os dados oficiais e observarmos a abrangência dessa discussão, pois, de acordo com o relatório divulgado pelo Fundo das Nações Unidas para a Infância (UNICEF), intitulado "A educação que protege contra a violência", podemos observar, no tópico "violência na escola", que "globalmente, cerca de 150 milhões de adolescentes entre 13 e 15 anos tiveram alguma experiência de violência, entre pares, dentro ou ao redor da escola. No Brasil, o entorno dessa instituição nem sempre é considerado seguro para as e os estudantes" (UNICEF Brasil, 2018, p. 21). O relatório aponta ainda que, segundo a Organização Mundial da Saúde (OMS), a cada 7 minutos, em algum lugar do mundo, uma criança ou um adolescente, entre 10 e 19 anos, é morto em consequência da violência, e que a maioria das vítimas são meninos negros, de baixa renda e que habitam as periferias urbanas.

Diante desses dados alarmantes sobre as violências que circundam os jovens na escola e para além dela, ainda é marcante a imagem que lhes é dada pela sociedade, que os vê com medo e com perplexidade. Nessas interpretações estereotipadas, parece existir certa dificuldade em considerar os jovens como capazes de formular questões significativas, de propor ações relevantes, de efetuar uma relação dialógica com outros atores, de contribuir para a solução dos problemas sociais, e vemos que, embora o "discurso dos direitos" sustente ações dirigidas à infância, à adolescência e à juventude, a compreensão que permeia os programas públicos é a de que os jovens são incompletos e incapazes de se guiarem por sua própria lógica, não sendo aptos para participar dos processos de invenção e negociação de seus próprios direitos (Silva, 2020). 
Entretanto, os jovens, em qualquer circunstância, são intermináveis, podendo ser continuamente metamorfoseados. Como, então, seria possível fixá-los em tabelas, criar-lhes rótulos, sendo eles móveis, mutantes e fugidios? “Um jovem já é a representação de muitos e, se ele não foi domesticado, é um povoamento" (SILVA; ADAD; SILVA, 2020, p. 2). Acreditamos, nesse sentido, que é preciso desfazer as identidades estigmatizantes produzidas sobre as juventudes ditas desiguais. Por isso, ao longo dos nossos trabalhos com/entre jovens, aprendemos que pesquisar e lidar com eles é possível desde que se acredite neles e em suas capacidades. Nesse caso, o trabalho da escola deve partir dos interesses dos estudantes e levar em conta o que eles gostam e sabem fazer e não especialmente suas carências e/ou faltas, por exemplo. Assim sendo, tomar os jovens como potência é percebê-los como sujeitos e protagonistas de sua própria história, contrariando as adversidades a que estão submetidos. São as maneiras de lidar com as adversidades que os tornam melhores, ao tomar suas vidas nas mãos, resistindo, valorizando e criando outras formas de vida capazes, portanto, de romper com a "perspectiva da falta" e as imagens estigmatizantes que os envolvem.

É com esse modo de reparar as situações evidentes, bem como com a posição de pensar os jovens como instância de formulação de ações propositivas, que nos perguntamos: o que pode a convivência escolar nesse contexto? Pode mobilizar processos de criação juvenis em combate à violência? O que fazem ou o que pensam os jovens diante das situações de violência na escola? Desse modo, acreditamos que uma das formas positivas e interessantes de discutir com os jovens essas questões é a utilização de variados estilos artísticos e literários, pois a arte é a elaboração da força vital que existe em nós. E isto significa que os valores serão outros se os adolescentes e jovens constituírem-se guerreiros plenamente preenchidos pela beleza da ética da existência, capazes de saírem de si e de se encontrarem com os outros, desconstruindo a forma de lógica perversa que os constituiu até agora: o individualismo e o narcisismo. Como nos ensinam Deleuze e Guattari (1992), é preciso criar novas armas, criar o intempestivo. $\mathrm{E}$ as armas que escolhemos e que mais nos ensinaram a viver, a conviver e a abraçar a vida foram a arte e o corpo, ao utilizarmos a Sociopoética em nossas pesquisas com os jovens e em nosso trabalho em sala de aula.

Assim, por meio da Sociopoética, objetivamos acompanhar as linhas de constituição do pensamento de jovens de uma escola pública sobre as violências na relação com a convivência no espaço escolar, visto que essa abordagem metodológica de pesquisa possibilita descobrir os problemas que, de modo não consciente, mobilizam os grupos sociais; favorece a criação de novos problemas ou de novas maneiras de problematizar a vida; e que, a partir da produção de confetos (conceitos + afetos), há interação e a participação ativas dos jovens na pesquisa, em meio à explosão de sentimentos e de emoções que tocam o modo como eles se trançam, misturam-se e constroem conhecimento coletivo.

\section{Metodologia: a Sociopoética como caleidoscópio para a Convivência Escolar}

A Sociopoética é uma teoria e prática da pesquisa e da aprendizagem que aponta para uma teoria social. Ela transgride a divisão instituída entre poesia, ciência, arte e a construção do conhecimento; não considera as pessoas envolvidas na pesquisa como possuidoras de saberes congelados, nem de ilusões fixadas; busca vivenciar para entender o momento criador, tanto do saber como das ilusões; solicita que as pessoas expressem o desconhecido, o recalcado, o escondido na superfície da pele, na rede nervosa ou na profundidade da víscera. Sendo assim, para que ocorra a produção dessa forma sensível de conhecimento, a Sociopoética é regida por cinco princípios básicos, quais sejam: pesquisar entre as pessoas de um grupo; pesquisar com/entre as culturas de resistência; enfatizar a potência do corpo e da arte na produção do conhecimento; valorizar a ética; e valorizar a espiritualidade no processo de investigação (Gauthier, 2015).

A partir dos princípios destacados, Silva (2018) ressalta a intrínseca relação entre eles, aos afirmar, por exemplo que os dispositivos artísticos utilizados no percurso metodológico de investigação tem como intuito fazer com que múltiplos sentidos do corpo falem, despertando novos modos de olhar, que podem ser percebidos pelo tato, pelo olfato, pela audição, 
despertando uma maneira inusitada, inesperada de produção de saberes e, portanto, de ciência, que perpassa e se expressa por todo o corpo. É valorizando as múltiplas formas de linguagem corporal que tornam-se ricas as possibilidades de dados neste método, sobretudo no que tange a valorização ética e espiritual das minorias marginalizadas.

Deste modo, é com base nos princípios Sociopoéticos que se torna possível a produção do pensamento do grupopesquisador, mediante a produção de confetos (conceitos perpassados de afetos), que têm a ver com nossas práticas, vivências e problemas, uma filosofia da vida coletiva, na qual o grupo-pesquisador se insere, e no qual não se atenta aos conceitos que já estão naturalizados, mas se preocupa com a produção de outras maneiras de problematizar o tema-gerador. Assim sendo, as oficinas sociopoéticas funcionam como planos de imanência para a criação dos confetos, levando os copesquisadores a problematizarem sobre o tema gerador a partir de dispositivos artísticos levados ao grupo (Silva, 2018). Nesse contexto, apresentamos os resultados de uma pesquisa sociopoética sobre o tema-gerador "as violências na relação com a convivência na escola", na qual o grupo-pesquisador foi constituído por nós, facilitadoras, e 11 jovens, entre 16 e 21 anos de idade, matriculados na $2^{\mathrm{a}}$ e $3^{\mathrm{a}}$ séries do Ensino Médio integrado aos cursos técnicos em Eventos, Produção de Moda, Contabilidade, Meio Ambiente e Recursos Humanos do Centro Estadual de Educação Profissional "Prefeito João Mendes Olímpio de Melo" PREMEN-NORTE, em Teresina-PI.

As questões que nos moveram e nos ajudaram a problematizar o tema-gerador foram: o que pensam os jovens sobre a relação entre a convivência e as violências nas escolas? Que implicações estabelecem na relação da convivência e das violências na escola? E o que pode o corpo do jovem na relação entre a convivência e as violências na escola? Na busca por essas respostas, realizamos quatro oficinas, sendo a primeira de negociação ${ }^{1}$, duas de produção de dados, e uma oficina de contra-análise ${ }^{2}$, que permitiram aos copesquisadores conhecer, confirmar, retificar e, especialmente, contrapor-se às nossas ideias. A técnica artística do Parangolé 3 das violências na convivência na escola foi a escolhida para a investigação, desdobrada em dois momentos: os Retalhos e o Parangolé das Violências na sua relação com a convivência na escola. Destacamos que as experiências investigativas que aqui transcrevemos formulam uma tríplice vertente de ensino, pesquisa e extensão, por meio das atividades do Observatório das Juventudes e Violências nas Escolas - OBJUVE, que se integra uma das linhas de atuação do Núcleo de Estudos e Pesquisas "Educação, Gênero e Cidadania", do Programa de Pós-Graduação em Educação - PPGEd, da Universidade Federal do Piauí - UFPI.

\section{Resultados e Discussão}

\subsection{Tipos de violências e seus efeitos no corpo dos jovens e na convivência na escola}

Durante a pesquisa, percebermos a potência dos relatos orais dos jovens, por intermédio da vivência das oficinas sociopoéticas, destacando aspectos importantes do seu filosofar, não aceitando respostas prontas e acabadas, mas inventando questionamentos por meio de múltiplos conceitos e saberes misturados às afecções mobilizadas pela arte. Assim sendo, evidenciamos alguns exemplos dos confetos produzidos que surgiram de momentos de problematização e criação dos copesquisadores em torno do tema-gerador "as violências na relação com a convivência na escola", tais como: confeto

\footnotetext{
${ }^{1} \mathrm{Na}$ Pesquisa Sociopoética os pesquisadores oficiais se transformam em facilitadores de oficinas e convidam o público-alvo a se tornar copesquisadores de um tema-gerador, a partir de uma negociação conjunta. Os que aceitarem o convite passam a investigar com o pesquisador-facilitador e a participar, com poder de decisão compartilhado, de todo o processo de pesquisa, inclusive da análise dos dados e da socialização da investigação. (Petit, 2014).

${ }^{2}$ Segundo Guathier (2015) a contra-análise é o momento em que o grupo-pesquisador estuda criticamente as hipóteses dos facilitadores sobre seu pensamento (sobre o inconsciente do seu pensamento), hipóteses pelas quais os facilitadores propõem problemas e confetos. É um momento dialógico.

${ }^{3}$ Parangolés são capas, estandartes, bandeiras para serem vestidas ou carregadas pelo participante. Da mesma forma que as casas construídas nas favelas, os Parangolés são feitos com as mais diferentes técnicas, dos mais diferentes materiais que, no entanto, parecem se esquecer do sentido de suas individualidades originais, ao se refundirem na totalidade da obra. Os Parangolés são compostos de materiais variados em cores, tamanhos e formas, texturas, interligados, revelados apenas quando a pessoa se movimenta. A cor ganha um dinamismo no espaço, por intermédio da associação com a dança e a música. A cor assume, desse modo, um caráter literal de vivência, reunindo sensação visual, táctil e rítmica. A obra só existe plenamente quando da participação corporal: a estrutura depende da ação. O participante vira obra ao vesti-lo, ultrapassando a distância entre eles, superando o próprio conceito de arte (Oiticica, 1986 apud Gonçalves, 2013, p. 89).
} 
Bagunça na cabeça dor da violência-carinha-triste-na-escola, que aponta a reflexão de uma pessoa que sofre a violência e o efeito desta na produção no corpo, da dor, da tristeza e da bagunça, como vemos a seguir:

Bagunça na cabeça dor da violência-carinha-triste-na-escola é a violência que produz sentimentos de dor, de tristeza e a bagunça que ficam na cabeça de uma pessoa que sofre violência, pois não sabe se vai fazer a mesma coisa que fizeram com ela, se ela não vai fazer nada, se ela vai tentar falar para alguém. São as ideias, pensamentos misturados, como: briga, discussão, apelidos e, às vezes, chega à escola os amigos ficam tirando sarro da cara dele por ter apanhado em casa.

Nesse sentido, para o grupo-filósofo, existe um processo de precarização das relações sociais como um todo dentro da escola, que se torna espaço de vivência da injustiça, do medo e da insegurança, quando não de pura reprodução dos valores racistas e sexistas de nossa sociedade. Essa cultura de violências, estabelecida no cotidiano escolar, marca a convivência e as relações pessoais juvenis, favorecendo o processo de banalização das diferentes formas de violências, tornando-as algo natural dentro da escola e mesmo da vida em sociedade das juventudes, desenvolvendo sobretudo nos jovens os sentimentos de tristeza, confusão e dor. Frente a isto, Silva e Negreiros (2020) consideram a violência como "uma das principais formas de representação de atos de incivilidade presentes na sociedade, violando um dos direitos da humanidade mais importantes, o direito à vida" (p. 328).

Em outro confeto, Formas de Violência-olhos-não-têm-um-nome-bocas-bullying, já vemos como destaque outro viés: as formas da violência a partir do olhar de um indivíduo para com o outro, que julga sem conhecer. São pessoas que falam mal dos outros, falam muitas coisas que machucam, falam sem pensar, por exemplo, quando uma pessoa que gosta de falar com todo mundo, de ser amiga de todo mundo, não gosta de ter inimigos, e tem gente que não gosta disso e fica falando mal dessa pessoa. Por isso, tem pessoas que sofrem com o preconceito, e o bullying, que é a violência que não se foca só em algo, porque pode ser por meio de apelidos, humilhações, atitudes ou preconceitos com a sexualidade. Esses confetos traduzem o que Bourdieu (1989) chama de capital simbólico, que tem relação com as diferentes modalidades de capital, para além do econômico, que inclusive não são imediatamente perceptíveis, pois seus efeitos de duração obedecem a uma lógica diferente, como as das violências verbais e a do bullying, estabelecidas por intermédio da intimidação da vítima, em um desequilibrado esquadrinhamento de poder no espaço escolar. Sobre isso, o grupo-pesquisador esboçou os efeitos de viver e sofrer com essas violências, sobretudo em casa e na escola, pois

[...] é uma sensação ruim, por conta de que é difícil estudar com várias coisas na cabeça, várias ideias, vários pensamentos negativos. Por exemplo, fico sozinha, sinto muito, pois gosto de ser rodeada de amigos, não gosto de ter inimigos, nunca gostei. Toda vez que entro em uma escola, gosto logo de fazer amizades, mas ficam jogando piadinhas, falando besteiras, falando coisas que não são verdade. Ser alvo de piadinhas na escola todos os dias deixa confusão na cabeça e nós somos vítimas desse tipo de piada, até na hora de entrar na escola. Isso atrapalha ao assistir aula, porque ser alvo de falatório, de piadas até mesmo das pessoas que andam com a gente, que são os primeiros a falarem, eu não desejo isso pra ninguém. O corpo se sente mal quando vivencia essas bocas e esses olhos violentos sobre ele, porque isso não é uma coisa boa, isso é uma coisa ruim.

Devido às intermináveis relações de poder e aos meios de coerção estabelecidos dentro das escolas, o grupo ressaltou pontos importantes sobre a questão do bullying. O termo em inglês se dá pelo motivo de não haver definições equivalentes em outras línguas. Entretanto, no Brasil, a Associação Brasileira Multiprofissional de Proteção à Infância e à Adolescência 
(ABARAPIA) destaca que a palavra tem sido compreendida como "comportamento agressivo entre estudantes", relacionado a práticas de intimidação, ameaça ou provocações. No entanto, Silva e Negreiros (2020) apresentam uma definição de bullying baseada na adoção de três características: comportamento agressivo ou de uma ofensa intencional; ocorrências repetidas e durante muito tempo; relações interpessoais caracterizadas por um desequilíbrio de poder.

Diante disso, o bullying se caracteriza por uma espécie de assédio moral na escola, em que agressores se utilizam de manipulações de relacionamentos, agressões verbais, exclusão, humilhação e ofensas com ataques físicos. O confeto Formas de Violência-olhos-Não-têm-um-nome-bocas-Bullying traz essa problemática, tomando como exemplo os calouros - aqueles que estão se inserindo na escola e que têm tempo estimado de três meses para aprenderem a conviver com bullying - sendo esse um tempo do ritual de passagem, adaptação e agrupamento dos jovens para fugir dessas violências ou, caso contrário, aprender a relevá-las, pois ninguém escolhe ter defeitos, mas com o passar do tempo vai aprendendo a lidar com as fragilidades e relevar várias coisas.

Diante dessas violências, os estudos mostram que as vítimas, na maioria das vezes, apresentam-se submissas, passivas e inseguras, além de sofrerem de baixa autoestima, características essas que são reveladoras de um processo de exclusão escolar, pois torna as vítimas oprimidas, amedrontadas e maltratadas, o que favorece o prolongamento das atitudes depreciativas pelos agressores, que fortalecem suas violências para com esses indivíduos, porque destoam dos padrões definidos pela sociedade ou porque são excluídos cultural e socialmente, como as mulheres, os negros, os homossexuais, os deficientes, as crianças obesas ou menos favorecidas economicamente, dentre outros. Sobre essas questões relacionadas ao preconceito e à discriminação, os jovens criaram confetos que evidenciam problemas vinculados à homofobia e à violência contra a mulher, destacados no confeto

Violência-flores-no-retalho-contra-a-mulher, que é a violência física e verbal às avessas na escola, aquela discriminação feita às meninas fortes que são apelidadas porque gostam de ficar com os meninos, não gostam de ficar com outras meninas, gostam de ficar na dela, gostam de coisas diferentes que não são ligadas à maquiagem, $e$, por isso, são discriminadas e todos pensam que elas "só querem ser".

Nesse confeto, o grupo destaca que as meninas, no âmbito escolar, também são vítimas de violência, aprisionadas em seu silêncio, preferindo não denunciar à justiça e/ou à autoridade uma vida de dor que as envergonha e as distingue negativamente. As instituições sociais, entre elas, a escola, moldam as identidades de gênero, de etnia dentro de perspectiva biológica, equivocada e preconceituosa, que rotula e exclui. Outro exemplo de violência na escola abrange o sofrimento e a angústia de jovens menos favorecidos economicamente, conforme o confeto Zig-Zag-da-convivência com violência-símbolodo-dinheiro, que é o preconceito na escola pela questão financeira, pela pessoa não ter nascido numa condição boa, mas que ainda assim não dá direito de a sociedade julgar alguém por isso, porque não se sabe o dia de amanhã, quando tudo pode mudar.

Todas essas violências intervêm no processo de ensino e de aprendizagem, além de causarem transtornos às relações sociais e, às vezes, consequências psicológicas para toda a vida. As vítimas não conseguem se defender devido ao fato de serem psicologicamente intimidadas e fisicamente mais fracas que seus agressores, portanto, a dor e o sofrimento cravados pelo bullying na vida dos jovens que sofrem com a sua ação são fortes, as constantes humilhações públicas, que hoje ganham ainda mais espaço devido às redes sociais, degradam rapidamente a imagem das crianças e dos adolescentes agredidos. Sobre isso, Miskolci (2018) constrói uma análise do processo de automatização de ferramentas digitais como instagram e facebook, que continuadamente induzem e divulgam postagens capazes de chamar a atenção por meio de apelo imagético e de conteúdo, de modo que vídeos e gravações são efetivamente vistos e enviados em rede de um jovem para outro, fazendo com que sua 
veracidade seja avaliada e julgada, frequentemente rompendo com os princípios básicos de respeito de direito a defesa e criação de argumentos contraditórios por aqueles que são ofendidos nas mídias digitais.

Essa forma de violência às vezes passa desapercebida, principalmente porque a crueldade presente nas relações interpessoais dentro da escola, onde os valentões se divertem por intermédio de insultos e da ridicularizarão dos mais fracos (seja nas redes sociais, ou na experiência diária da vida escolar), são tidos como brincadeiras de mau gosto, e não entendidos suficientemente como problemas a serem discutidos entre os jovens e seus pares, e entre os responsáveis pelo menores agressores com o corpo docente também, de modo a pensar alternativas para as violências acometidas. Se não encontrados meios de combater tais problemas, acreditamos que isso acarretará no enfraquecimento da autoestima daqueles que são vitimados pelas agressões, inclusive com marcas e traumas dolorosos pelo restante de suas vidas, pois Adad (2014) ressalta que a dor que acomete os jovens por traumas vinculados as experiências com bullying estão ligadas ao ressentimento e à mágoa, constituindo um corpo amargo e triste, que vive em função da repetição de seu sofrimento e da sua dor. No confeto Zig-Zag-da-convivência com violência, os jovens falam sobre como o sofrimento abala o corpo fisicamente e psicologicamente:

Zig-zag-da-convivência com a violência é aquela convivência zig-zag na vida da pessoa, pois geralmente o percurso que ela percorre não é sempre o mesmo, em determinados percursos da vida acontecessem muitas coisas, que podem ser o sofrimento de preconceito pelo dinheiro, problemas que levam à depressão ou ficar abalado, seja fisicamente ou psicologicamente, ou mesmo alguns problemas do coração, porque além da vida de estudante, existe a vida do trabalhador e a particular, onde tem a privacidade e os problemas com as amizades ou os namorados.

Nesse confeto, vemos que há vários sofrimentos no percurso de vida dos jovens, e, sobre isso, Adad (2014) ainda nos alerta para o sentido reativo desse sofrimento, podendo levar o jovem a pensar no que vai fazer, esquematizando uma reação de vingança, que vai crescendo por intermédio dos ressentimentos, do medo e da inimizade que invadem o seu inconsciente, que se rebela contra a violência. O corpo fica armado, cheio de tensão e violência. As memórias desses jovens são como uma prisão, que manipula o pensamento para fome e sede por vingança, de um corpo que cansado de tantas humilhações em um vazio de palavras, por conta do não diálogo e da falta da escuta por parte de todos os que formam a escola, prefere silenciar a argumentar sobre sua falta de voz e o acúmulo de ações agressivas que o fazem criar forças para revidar e disseminar o ódio e o temor. Nessa faceta, podemos enquadrar desde os xingamentos, alguns atos de indisciplinas e agressões verbais, e as físicas, como socos, tapas e empurrões que, muitas vezes, são banalizados, e a escola pouco procura saber a história que gerou uma situação de conflito, punindo todos que transgridem as regras, sem analisar os motivos que estão por trás do problema.

Acreditamos ser necessário que, quando um jovem agir com violência, essa ação seja responsabilidade de todos, e que a situação seja analisada de forma que possamos compreender os reais motivos que o levaram a agir de forma violenta, até mesmo para que a escola possa desenvolver a cultura de paz entre os alunos. Assim, ela precisa conhecê-los, e, somente a partir disso, poderá desenvolver valores éticos que trabalhem o respeito mútuo, a tolerância e a paz, tendo a preocupação de dar visibilidade às questões de afirmação da dignidade do outro, pois o diálogo, a comunicação e a negociação são pilares básicos para a mediação e a educação com/entre jovens.

\section{Conclusão}

A partir desta investigação, compreendemos que a Sociopoética é um dispositivo inovador no trabalho educativo dentro da escola para combater as situações de violência e conflito, pois permite um novo entendimento sobre os jovens, revelando o seu protagonismo social por meio da visibilidade que proporciona ao seu pensamento, que aqui esteve permeado 
de afeç̧̃̃es, tendo em vista que foi estimulado pela arte e pelo corpo como canal de expressão humana - dispositivos que potencializam o protagonismo juvenil, resultando na criação de saberes coletivos pelas juventudes relevados nos confetos que apresentamos.

Acreditamos que a vivência da Sociopoética no Centro de Educação Profissional "Prefeito João Mendes Olímpio de Melo" PREMEN-NORTE levou os jovens a pensarem e a dialogarem sobre o que thes aflige em seu dia a dia, possibilitando a criação dos confetos que denunciaram vários tipos de manifestação de violências, como as questões raciais, homofóbicas, de submissão feminina, desigualdades sociais e econômicas, além dos ligados à fragilidade da convivência na escola. Isso foi possível devido à escuta sensível e à disseminação do diálogo entre o grupo-pesquisador, pois estimulou as falas dos jovens e os ajudou a desabafar e a pensar os problemas comumente silenciados em suas mentes, afirmando a potência dos coletivos juvenis e da riqueza dos seus pensamentos e significações.

Por meio da técnica sociopoética do Parangolé, foi possível entrecruzarmos possibilidades de pensamentos do grupo participante de nossa investigação que, ao final de tudo, acabou por levantar mais questionamentos e interrogações, que foram trabalhadas em meio a uma multiplicidade de confetos, como, por exemplo: Bagunça na cabeça dor da violência-carinhatriste-na-escola, Violência-flores-no-retalho-contra-a-mulher, Zig-Zag-da-convivência com violência, entre outros que destacam as violências estabelecidas no cotidiano escolar, com a convivência e suas relações pessoais, criticando a banalização das diferentes formas de violências que têm levado a escola a ser consumida por diversos conflitos.

Dessa forma, concluímos este trabalho, convidando os jovens, pesquisadores, professores, enfim, as pessoas presentes na escola, a serem sementes de paz enquanto promotores de vida. E que esta paz não seja qualquer paz, nem qualquer vida, mas aquela que nos tira do sossego de um mundo anestesiado e nos faz guerreiros de mundos diversos, múltiplos, infinitamente capazes de modificar valores. Essa é a condição para que os jovens possam viver, e viver uma vida que lhes faça sentido, na qual não precisem ter vergonha de seus corpos e subjetividades, mas que, em suas próprias singularidades, possam, com leveza, ser o que verdadeiramente são seja na escola, seja na vivência com/no mundo.

\section{Referências}

Adad, S. J. H. C. (2014). A Sociopoética e os cinco princípios. In S. J. H. C. Adad, S. H. Petit, I. do Santos \& J. Gauthier (Orgs.), Tudo que não inventamos é falso: dispositivos artísticos para pesquisar, ensinar e aprender com a Sociopoética (pp. 41-59). Fortaleza: EdUECE.

Bourdieu, P. (1989). O poder simbólico (2nd ed.), Editora Bertrand Brasil.

Brasil. (2019). Atlas da violência 2019. Rio de Janeiro, São Paulo: Instituto de Pesquisa Econômica Aplicada, Fórum Brasileiro de Segurança Pública. http://www.ipea.gov.br/portal/images/stories/PDFs/relatorio_institucional/190605_atlas_da_violencia_2019.pdf

Brasil. (2020). Atlas da violência 2020. Rio de Janeiro, São Paulo: Instituto de Pesquisa Econômica Aplicada, Fórum Brasileiro de Segurança Pública. https://www.ipea.gov.br/atlasviolencia/

Deleuze, G. \& Guattari, F. (1992). Conversações (P. P. Pelbart, Trad.). Ed. 34.

Diógenes, G. (2020). Cidade, arte e criação: novos diagramas de culturas juvenis da periferia. Estud. av., 34 (99), $373-389$.

Gauthier, J. (2015). Sociopoética: encontro entre arte, ciência e democracia na pesquisa em ciências humanas e sociais, enfermagem e educação. AnnaNery/UFRJ.

Gonçalves, M. G. (2013). Pensar é seguir a linha de fuga do voo da bruxa: pesquisa Sociopoética com estudantes de direito sobre a arte na formação do jurista. (Tese de Doutorado em Direito). Programa de Pós-Graduação em Direito Estado e Constituição PPGB, Universidade de Brasília (UNB), Brasil.

Miskolci, R. (2018). Sociologia digital: notas sobre pesquisa na era da conectividade. Contemporânea. 6(2), 275 - 297.

Petit, I. (2014). sociopoética: potencializando a dimensão poiética da pesquisa. In S. J. H. C. Adad, S. H. Petit, I. do Santos \& J. Gauthier (Orgs.), Tudo que não inventamos é falso: dispositivos artísticos para pesquisar, ensinar e aprender com a Sociopoética (pp. 41-59). Fortaleza: EdUECE.

Silva, K. S. (2018). Manobras sociopoéticas: aprendendo em movimento com skatistas do litoral do Piauí. EDUECE.

Silva, M. S. B., Adad, S. J. H. C., \& Silva, K. S. (2020). Juventudes, comunidades periféricas, direitos humanos e educação. Research, Society and Development, $9(10), 1-16$. 
Research, Society and Development, v. 10, n. 8, e16610817048, 2021

(CC BY 4.0) | ISSN 2525-3409 | DOI: http://dx.doi.org/10.33448/rsd-v10i8.17048

Silva, M. S. B. (2020). Vida nua, Direitos Humanos e Educação em tempos de Tanatopolítica. Research, Society and Development, 9(8), 1-16.

Silva, E. H. B. S., \& Negreiros, F. (2020). Violências nas escolas públicas brasileiras: uma revisão sistemática da literatura. Revista Psicopedagogia. 37(114), $327-340$.

UNICEF Brasil. (2018). Fundo das Nações Unidas para a Infância. A educação que protege contra a violência. UNICEF Brasil. https://www.unicef.org/brazil/media/4091/file/Educacao_que_protege_contra_a_violencia.pdf 